\title{
Plasma Advanced Glycation End Products (AGEs), Receptors for AGEs and Their Correlation with Inflammatory Markers in Middle School-Age Children
}

\author{
S. Accacha ${ }^{a}$ W. Rosenfeld ${ }^{a} \quad$ A. Jacobson ${ }^{b} \quad$ L. Michel ${ }^{a} \quad$ F.J.Schnurr ${ }^{a}$ \\ S. Shelov ${ }^{c, d}$ S. Ten ${ }^{d}$ C. Boucher-Berry ${ }^{e}$ D.E. Carey ${ }^{e}$ P.W. Speiser ${ }^{e} \quad$ B. Lowell ${ }^{d}$ \\ R. Conroy ${ }^{f} \quad$ M. Klein ${ }^{g} \quad$ I. Fennoy ${ }^{f} \quad$ R. Rapaport ${ }^{g} \quad$ M. Rosenbaum ${ }^{f}$ \\ a Pediatrics, ${ }^{b}$ Research Institute, and ' Office of Undergraduate Medical Education, Winthrop University Hospital, \\ Mineola, N.Y., dPediatrics, Maimonides Medical Center, Brooklyn, N.Y., e Pediatrics, Cohen Children's Medical Center,

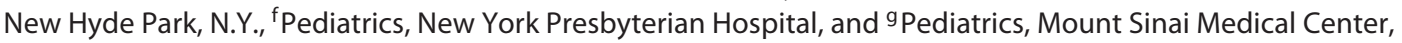 \\ New York, N.Y., USA
}

\section{Key Words}

$\mathrm{N}^{\varepsilon}$-(carboxymethyl)lysine · Soluble RAGE · Endogenous secretory RAGE · Pediatric obesity · Insulin resistance

\begin{abstract}
Aim: Advanced glycation end products (AGEs) and/or their receptors (RAGE) are significantly positively correlated with adiposity, inflammation, dyslipidemia, and insulin resistance in adults. However, the relationships between AGEs, RAGE, and adiposity-related comorbidites in children have not been well studied. Methods: In a cross-sectional study of 88 children (age 11-15 years) from the New York area enrolled in the Reduce Obesity and Diabetes (ROAD) study, we examined the correlation of the AGE $\mathrm{N}^{\varepsilon}$-(carboxymethyl)lysine $(\mathrm{CML})$, soluble RAGE (sRAGE), and endogenous secretory RAGE (esRAGE) with adiposity, inflammatory markers [interleukin-6 (IL-6), C-reactive protein, tumor necrosis factor-a], adiponectin, lipids, insulin sensitivity, and insulin secretory capacity. Results: Pediatric CML levels were $~ 20 \%$ below average adult levels. CML was significantly $(p<0.05)$ positively correlated with age and insulin sensitivity and negatively with adiposity, dyslipidemia and IL-6. sRAGE correlated pos-
\end{abstract}

\section{KARGER}

E-Mail karger@karger.com

www.karger.com/hrp itively with esRAGE and negatively with adiposity and IL-6. Both sRAGE and esRAGE correlated negatively with insulin secretory capacity. Conclusion: Our findings suggest that unlike adults, CML is negatively associated with adiposity and adiposity-related comorbidity risk in children. As in adults, sRAGE and esRAGE were, to varying degrees, negatively correlated with body fatness and risk factors for adiposity-related comorbidities.

(c) 2013 S. Karger AG, Basel

\section{Introduction}

The increasing prevalence of pediatric obesity (and its attendant comorbidities) has become one of the most important public health issues in the United States [1]. Many obesity-related complications, such as fatty liver and type 2 diabetes that were previously thought to be exclusively adult diseases are now frequently seen in children [2]. Obesity in childhood has been reported to be a predictor of mortality and adiposity-related comoribidity risk in adults even if pediatric obesity does not persist into adulthood [1]. 
The pathogenesis of adiposity-related comorbidities is most likely the result of multiple convergent and coordinate pathways that affect endothelial function, vascular tone, insulin sensitivity, insulin secretory capacity and any of the other multiple systems that are potentially adversely affected by increasing adiposity [3]. One of the wellcharacterized pathways in adults involves the generation of oxidative stress and subsequent induction of inflammation and thrombosis via accumulation of advanced glycation end products (AGEs) which are a product of nonenzymatic glycation [4]. In humans, AGEs have been chemically characterized by the detection of pentosidine, methylglyoxal and $\mathrm{N}^{\varepsilon}$-(carboxymethyl)lysine (CML) [4].

AGEs interact with the receptor RAGE, which is a 35$\mathrm{kDa}$ transmembrane specific cell surface protein in the immunoglobulin superfamily that is expressed in a number of cell lines including endothelial, mesangial, smooth muscle, and mononuclear cells [5]. The AGE-RAGE interactions cause activation of the transcription factor nuclear factor- $\mathrm{\kappa B}$, inducing oxidative stress and inflammatory reactions and increased RAGE expression in multiple tissues [5]. Isoforms of the full-length RAGE, which lack the transmembrane and signaling domain, are found in the extracellular domains in two different forms, soluble RAGE (sRAGE) and a C-truncated variant known as endogenous secretory RAGE (esRAGE) [6,7], which are detectable in plasma. Both esRAGE and sRAGE are able to bind circulating RAGE ligands and act as ligand decoys, thus potentially diminishing the proinflammatory effects were these ligands to interact with the full-length cell surface RAGE. In adults, lower circulating concentrations or sRAGE and esRAGE are associated with conditions such as type 1 diabetes, obesity, and rheumatoid arthritis that are characterized by high concentrations of circulating proinflammatory ligands [7].

The relationship of AGEs, sRAGE and esRAGE to markers of other adiposity-related disease states has been studied extensively in the adult population. AGEs are positively correlated with circulating concentrations of $\mathrm{C}$-reactive protein (CRP), albuminuria, and components of the metabolic syndrome [waist circumference, insulin resistance, blood pressure, HDL cholesterol (HDL) and triglycerides (TG)] in adults [8]. Circulating concentrations of RAGE are positively correlated with the level of AGEs and increased expression and circulating concentrations of inflammatory markers such as tumor necrosis factor- $\alpha$ (TNF- $\alpha$ ), interleukin-1 (IL-1) and IL-6 [9].

In children, the links between AGEs, their receptors (sRAGE and esRAGE) and obesity and adiposity-related comorbidities are not well defined. Few pediatric studies report varying results as to the correlations of AGEs, their receptors, adiposity and adiposity-related comorbidity risk $[7,10,11]$. Our initial hypothesis was that in children the relationship of AGEs and RAGE to adiposity, inflammation, lipids, and glucose homeostasis would be similar to that seen in adults [12].

\section{Materials and Methods}

\section{Study Overview}

This is part of a multi-site 5-year study of a multi-ethnic population of middle school students in 5 New York City public schools implemented by a collaborative research consortium called the Reduce Obesity and Diabetes (ROAD) project which was assembled through the Academy for Medical Development and Collaboration (AMDeC, New York, N.Y., USA) [13]. The collaborators were researchers at Winthrop University Hospital, Columbia University Medical Center, Mt. Sinai Medical Center, Cohen Children's Medical Center, and Maimonides Medical Center. This study was approved by the Institutional Review Board of all relevant institutions as well as the New York City Board of Education and is consistent with guiding principles for research involving humans [14]. Written informed consent was obtained from the parents or legal guardians, and written informed assent was obtained from each subject. Detailed methods for this study have been previously published [13].

\section{Subjects}

An initial population of 619 subjects was divided into 4 groups: African-American, Caucasian, Hispanic, and Asian-American. For this sub-study, subjects were selected from initial screening tests performed in the fall of the first year they were enrolled. Within each group, subjects were ranked from the lowest to the highest values for measures of insulin secretion and resistance [glucose disposal index (GDI), acute insulin response (AIR), homeostasis model of assessment for insulin resistance (HOMA-IR)]. Subjects in the first 3 groups with the highest HOMA-IR in each 10th percentile rank were chosen, followed by the highest GDI in each 10th percentile rank to generate a total of 22-25 subjects per group. In the case of Asian-Americans, a similar procedure was used for the highest values of HOMA-IR and GDI in each 5th percentile rank to generate a total of 120 subjects to include a mixed population of East Asians (from China, Japan, Taiwan, and Korea) and South Asians (from India, Pakistan, Sri Lanka, Bangladesh).

After identification of this cohort, prospective data exclusion criteria were outliers for fasting insulin values or inflammatory markers (CRP, TNF- $\alpha$, or IL-6) $>3$ standard deviations (SD) above the mean, assuming that such participants were probably not fasting or were ill. Exclusion criteria were fasting insulin $>30 \mathrm{mIU} / \mathrm{ml}$, CRP $>32.6 \mathrm{pg} / \mathrm{ml}$, TNF- $\alpha>9.6 \mathrm{pg} / \mathrm{ml}$, or IL-6 $>4.2 \mathrm{pg} / \mathrm{ml}$. Twelve subjects were excluded based on these specific indices, and an additional 2 subjects were excluded because of insufficient sample collection. As described in 'Results', circulating concentrations of CML are significantly lower in children than in adults and an additional 18 data sets were not included in the analysis due to CML values outside of the lowest range of the assay. All of these exclusions were made prospectively, and the final population for which 
data are analyzed consisted of 88 students ( 51 males, 37 females). Height, weight, body mass index (BMI), age, gender, and ethnicity/ race of enrolled subject populations for each school were compared with the known demographics for that school to ascertain that there was no bias in subjects who consented to enroll [15].

\section{Procedures}

Comorbidity risk was assessed by family history, anthropometry, and biochemical evaluation of lipids, glucose homeostasis, and inflammation. A medical and family history questionnaire including age, ethnicity, gender, family history of obesity, hypertension, and diabetes, as well as the subject's current medication and health problems, was completed by each participant and their caregivers. This information was then reviewed with the parent or legal guardian either in person or over the phone. All students underwent anthropometric measurements including weight (light clothes, no sweaters, jackets or shoes), height, and waist circumference (obtained at the level just above the iliac crest) on the morning of the study. Body composition was analyzed by bioelectrical impedance (Body Fat Analyzer, Model HBF-306, Omron, Gays Mills, Wisc., USA).

Students were studied in the fasting state between 09.00 and 10.00 for fasting glucose, insulin, CRP, IL-6, total cholesterol, HDL, LDL cholesterol (LDL), and TG levels, as well as adiponectin (ACRP30), sRAGE, esRAGE and CML. Students received a standard intravenous glucose load $(0.5 \mathrm{~g} / \mathrm{kg}$, maximum $25 \mathrm{~g})$ over 3-4 min, and blood was drawn for insulin at 1, 3 and 5 min after glucose administration.

\section{Laboratory Analyses}

CML is one of the most prevalent AGEs, and is considered a representative marker of glycosylation in numerous animal and human studies [5]. Serum CML was measured by enzyme-linked immunosorbent assay (ELISA; MicroCoat GmbH, Bernried, Germany), with intraassay precision of 3.0\% and interassay precision of $4.0 \%$. sRAGE was measured by ELISA (R\&D Systems, Minneapolis, Minn., USA) with intraassay precision of $4.7-6.0 \%$ and interassay precision of $6.1-8.7 \%$, and esRAGE was measured by ELISA (B Bridge International) with intraassay precision of $3.0 \%$ and interassay precision of $5.0 \%$. Total cholesterol was determined by autoanalyzer (Integra 400 Plus, Roche Diagnostics, Indianapolis, Ind., USA). Sensitivity is $0.12 \mathrm{mg} / \mathrm{dl}$. Intra- and interassay precision is 0.5 and $1.9 \%$, respectively. HDL was determined by autoanalyzer (Integra 400 Plus). Sensitivity is $3 \mathrm{mg} / \mathrm{dl}$. Intra- and interassay precision is 1.0 and $1.3 \%$, respectively. TG were determined by autoanalyzer (Integra 400 Plus). Sensitivity is $8.85 \mathrm{mg} / \mathrm{dl}$. Intraand interassay precision is 1.6 and $1.9 \%$, respectively. LDL-direct was calculated from total cholesterol, HDL and TG using the Friedewald formula. Glucose was determined by autoanalyzer (Integra 400 Plus). Sensitivity is $2.16 \mathrm{mg} / \mathrm{dl}$. Intra- and interassay precision is 0.8 and $1.4 \%$, respectively. Insulin was measured by CLIA (Immulite 1,000, Siemens Healthcare Diagnostics, Deerfield, Ill., USA). Sensitivity is $2 \mathrm{mIU} / \mathrm{ml}$. Intra- and interassay precision is 4.3 and $5.3 \%$ respectively. Adiponectin was measured by radioimmunoassay (Millipore, Millerica, Minn., USA). Sensitivity is 0.8 $\mathrm{ng} / \mathrm{ml}$. Intra- and interassay precision is 6.2 and $6.9 \%$, respectively. IL-6 was measured by ELISA (R\&D Systems). Sensitivity is $0.04 \mathrm{pg} /$ $\mathrm{ml}$. Intra- and interassay precision is 7.2 and $7.8 \%$, respectively. CRP was measured by turbidimetrics (Roche Diagnostics). Sensitivity is $0.04 \mathrm{pg} / \mathrm{ml}$. Intra- and interassay precision is $1.3 \%$ and 3.1 $\mathrm{pg} / \mathrm{ml}$, respectively. TNF- $\alpha$ was measured by ELISA (R\&D Systems). Sensitivity is $0.5 \mathrm{pg} / \mathrm{ml}$. Intra- and interassay precision is 5.9 and $12.6 \%$, respectively. Estradiol and testosterone were measured by CLIA (Immulite 1,000, Siemens Healthcare Diagnostics). Sensitivities for estradiol and testosterone are $15 \mathrm{pg} / \mathrm{ml}$ and $15 \mathrm{ng} / \mathrm{dl}$, and intraassay precisions are 5.1 and $8.9 \%$, respectively.

\section{Calculations}

Fat mass was calculated from the weight and percent body fat using the following equation: [ fat mass $=($ weight in $\mathrm{kg}) \times(\%$ body fat)/100]. Insulin sensitivity was measured as the Qualitative Insulin Sensitivity Check Index [QUICKI, (1/log fasting insulin $\times \log$ fasting glucose)] [16]. As in our previous work [15], QUICKI was prospectively chosen as the primary index of insulin sensitivity based on the work of Katz et al. [16].

Phase 1 insulin release was measured as AIR (mean rise in insulin 3 and 5 min after i.v. dextrose) [17]. Because insulin sensitivity and insulin release are significantly positively correlated [15, 18], insulin secretory capacity adjusted for insulin sensitivity was calculated as the GDI [ $\log _{10}(\mathrm{AIR} \times$ fasting glucose/fasting insulin) $]$ as described previously [15].

\section{Statistical Analyses}

Data are presented as mean \pm SD unless otherwise indicated. Whenever possible, data were converted into $\mathrm{z}$-scores to control for the effects of age and gender. This was done for BMI and waist circumferences as indices of adiposity and truncal adiposity, and for total cholesterol, TG, HDL, and LDL for lipids. More specifically, BMI z-scores were calculated using the EpiInfo 2,000 program from the Centers for Disease Control which is based on growth charts smoothed using the LMS method [19]. Z-scores for laboratory values and waist circumference were calculated as zscore $($ or SD score $)=($ observed value - median value of the reference population)/SD value of reference population $[20,21]$.

Multiple linear regression analyses were performed, and partial correlation coefficients were calculated using the entire data set for $\log _{10}$ CML, sRAGE and esRAGE as independent variables, and measures of glucose homeostasis, lipids, and inflammation as individual dependent variables. Similar analyses were conducted using BMI Z-score as an independent variable and $\log _{10} \mathrm{CML}$, sRAGE and esRAGE as a dependent variable. This technique significantly reduced the number of comparisons being made. CML data were log-transformed to ensure normality of distribution. Our initial hypotheses were that CML, sRAGE and esRAGE are significantly correlated with fat (BMI z-score), truncal adiposity (waist circumference $\mathrm{z}$-score), insulin resistance (QUICKI), insulin secretory capacity (GDI), lipids and inflammatory markers. Because these dependent variables are all interrelated, post-hoc adjustments, which assume that the tests are independent, were not made [22-24]. Correlation coefficients were calculated among: (1) $\log _{10}$ CML, sRAGE and esRAGE as independent variables, (2) measures of adiposity as dependent variables, and (3) measures of glucose homeostasis and inflammation as dependent variables. In the event that both circulating concentrations of $\log _{10} \mathrm{CML}$, sRAGE and esRAGE and other variables were found to be significantly correlated with adiposity, we performed an analysis of covariance (ANCOVA) adding age, gender, and percent body fat as covariates. Statistical significance was prospectively defined as $\mathrm{Pa}$ $<0.05$. All $p$ values $<0.10$ are reported. Concentrations of CML, sRAGE and esRAGE in this study were compared with data from 
adult studies because of the possibility of nonlinearity of the relationships of these variables to fat mass and risk factor of adiposityrelated comorbidities [25].

\section{Results}

Clinical and metabolic characteristics of subjects who were included or excluded (based on prospectively set criteria) are presented in table 1 . The only significant difference between the included and excluded groups was that AIR and HOMA-IR were significantly higher in the excluded group, most likely due to exclusion based on elevated fasting insulin levels.

\section{Anthropometric and Gender Data}

Fifty one males and 37 females were included in the sub-study. Forty-four percent of students (23 males, 16 females) were overweight (BMI $>85$ th percentile for age and gender) or obese (BMI $>95$ th percentile for age and gender) and $31 \%$ of students reported a first- or seconddegree relative with type 2 diabetes mellitus. Compared to females, males were significantly taller [160 (10) vs. 155 (7) $\mathrm{cm}, \mathrm{p}=0.013]$, had a higher fasting glucose level [94 (7) vs. 91 (7) $\mathrm{mg} / \mathrm{dl}, \mathrm{p}=0.045]$, and significantly lower circulating concentrations of adiponectin [11.1 (4.0) vs. $14.4(4.7) \mu \mathrm{g} / \mathrm{ml}, \mathrm{p}=0.001]$. No significant gender differences were detected in CML, sRAGE, or esRAGE levels, lipids, or variables related to anthropometry, glucose homeostasis, lipids, or inflammatory status.

\section{Correlation of $\log _{10} C M L$ with Anthropometric Data} and Metabolic Markers

CML data were not normally distributed and therefore correlation analyses are presented only in reference to $\log _{10}$ (CML; see tables 1 and 2). $\log _{10}$ CML was significantly positively correlated with age $(r=0.42, p<0.0001$; fig. 1a), and negatively correlated with waist circumference $\mathrm{z}$-score $(\mathrm{r}=-0.24, \mathrm{p}=0.02$; fig. $1 \mathrm{~b})$. $\log _{10} \mathrm{CML}$ was negatively and weakly correlated with percent fat $(\mathrm{r}=-0.2$, $\mathrm{p}=0.07)$. CML and $\log _{10}$ CML were significantly positively correlated with age $(\mathrm{r}=0.42, \mathrm{p}<0.0001)$ and QUICKI $(r=0.23, p=0.03)$. Possible effects of puberty were examined by looking for correlations of testosterone in males and estradiol in females with CML, sRAGE, and esRAGE. No significant correlations were observed with testosterone levels in males or estradiol levels in females.

When analyzed relative to biochemical data, $\log _{10}$ CML was significantly negatively correlated with LDL $(\mathrm{r}=-0.23, \mathrm{p}=0.03)$ and IL-6 $(\mathrm{r}=-0.32, \mathrm{p}=0.003)$. Be-

AGE, RAGE and Comorbidity Risk Factors in Children
Table 1. Anthropometric data for all study subjects

\begin{tabular}{|c|c|c|}
\hline Variable & $\begin{array}{l}\text { Subjects } \\
\text { included }\end{array}$ & $\begin{array}{l}\text { Subjects } \\
\text { excluded }\end{array}$ \\
\hline \multicolumn{3}{|l|}{ Demographics } \\
\hline Total & 88 & 32 \\
\hline Males/females & $51 / 37$ & $21 / 11$ \\
\hline Age, years & $12.9(0.9)$ & $13.0(0.9)$ \\
\hline Weight, kg & $57.8(15.3)$ & $56.9(16.2)$ \\
\hline Height, $\mathrm{cm}$ & $158.4(8.8)$ & $159.6(9.9)$ \\
\hline $\mathrm{BMI}, \mathrm{kg} / \mathrm{m}^{2}$ & $22.7(4.7)$ & $22.1(5.4)$ \\
\hline BMI z-score & $0.87(0.95)$ & $0.78(1.10)$ \\
\hline Waist, cm & $77.4(12.8)$ & $76.2(12.9)$ \\
\hline Waist z-score & $0.63(1.0)$ & $0.56(1.1)$ \\
\hline Body fat, $\%$ & $28.3(7.9)$ & $26.7(7.3)$ \\
\hline Fat mass, kg & $17.1(8.3)$ & $16.7(7.9)$ \\
\hline \multicolumn{3}{|l|}{ Lipids } \\
\hline Total cholesterol, mg/dl & $164(30)$ & $168(37)$ \\
\hline Cholesterol z-score & $0.12(0.84)$ & $0.13(0.92)$ \\
\hline $\mathrm{TG}, \mathrm{mg} / \mathrm{dl}$ & $77(37)$ & $74(29)$ \\
\hline TG z-score & $-0.01(0.65)$ & $-0.03(0.77)$ \\
\hline $\mathrm{HDL}, \mathrm{mg} / \mathrm{dl}$ & $54(12)$ & $50(12)$ \\
\hline HDL z-score & $0.27(0.87)$ & $0.22(0.95)$ \\
\hline LDL, mg/dl & $95(26)$ & $104(32)$ \\
\hline LDL z-score & $0.06(0.39)$ & $0.19(0.42)$ \\
\hline \multicolumn{3}{|l|}{ Glucose homeostasis } \\
\hline Glucose, mg/dl & $93(7)$ & $94(6)$ \\
\hline Insulin, $\mathrm{mIU} / \mathrm{ml}$ & $9.4(5.2)$ & $12.0(11.4)$ \\
\hline QUICKI & $0.35(0.03)$ & $0.34(0.06)$ \\
\hline GDI & $2.88(0.28)$ & $2.95(0.33)$ \\
\hline $\mathrm{AIR}, \mathrm{mIU} / \mathrm{ml}$ & $88.3(70.1)$ & $148.7(154.9)^{*}$ \\
\hline HOMA-IR & $2.45(4.51)$ & $2.95(2.62)^{*}$ \\
\hline \multicolumn{3}{|l|}{ Inflammatory markers } \\
\hline Adiponectin, $\mu \mathrm{g} / \mathrm{ml}$ & $12.5(4.5)$ & $10.5(5.6)$ \\
\hline IL-6, pg/ml & $1.05(0.68)$ & $0.92(0.55)$ \\
\hline CRP, ug/ml & $3.97(5.16)$ & $2.77(2.67)$ \\
\hline TNF- $\alpha, p g / m l$ & $1.93(1.57)$ & $2.15(1.62)$ \\
\hline \multicolumn{3}{|l|}{ Sex steroids } \\
\hline Testosterone (males), ng/dl & $121.4(163.5)$ & $157.7(197.5)$ \\
\hline Estradiol (females), pg/ml & $33.1(41.9)$ & $46.1(59.2)$ \\
\hline $\mathrm{CML}, \mu \mathrm{g} / \mathrm{ml}^{1}$ & $423.9(153.8)$ & \\
\hline $\log _{10} \mathrm{CML}^{1}$ & $2.60(0.15)$ & \\
\hline sRAGE, $\mathrm{pg} / \mathrm{ml}^{1}$ & $1,095.7(427.7)$ & \\
\hline esRAGE, $\mathrm{pg} / \mathrm{ml}^{1}$ & $310.4(129.8)$ & \\
\hline
\end{tabular}

Values are expressed as mean (SD) unless otherwise indicated. $* \mathrm{p}<0.05$ vs. included group.

${ }^{1}$ CML, sRAGE, and esRAGE data not reported for excluded group since the majority were excluded based on values for these variable that were outside the range of assay sensitivity.

cause $\log _{10}$ CML was negatively correlated with body fatness and age, data were also analyzed by multiple regression analysis to 'correct' for BMI z-score. After this correction, the correlation between $\log _{10} \mathrm{CML}$ and LDL (semipartial $\mathrm{r}=-0.22, \mathrm{p}=0.047$ ) and IL-6 (semipartial $\mathrm{r}=-0.31, \mathrm{p}=0.005$; fig. 1c) remained significant (table 2). 
Table 2. Correlation of $\log _{10} \mathrm{CML}$, sRAGE and esRAGE with significant and near-significant independent variables

\begin{tabular}{|c|c|c|c|c|c|c|}
\hline & \multicolumn{2}{|c|}{$\log _{10} \mathrm{CML}$} & \multicolumn{2}{|c|}{ sRAGE, pg/ml } & \multicolumn{2}{|c|}{ esRAGE, ng/ml } \\
\hline & $\mathrm{r}$ & $\mathrm{p}$ & $\mathrm{r}$ & $\mathrm{p}$ & $\mathrm{r}$ & $\mathrm{p}$ \\
\hline Age (years) & 0.42 & $<0.0001$ & & & & \\
\hline $\mathrm{BMI}, \mathrm{kg} / \mathrm{m}^{2}$ & & & -0.30 & 0.004 & & \\
\hline \multicolumn{7}{|l|}{ BMI z-score } \\
\hline Percent body fat & -0.2 & 0.07 & -0.30 & 0.003 & & \\
\hline Fat mass (kg) & & & -0.36 & 0.0007 & & \\
\hline Waist $(\mathrm{cm})$ & & & -0.22 & 0.04 & & \\
\hline Waist z-score & -0.24 & 0.02 & -0.23 & 0.03 & & \\
\hline \multicolumn{7}{|l|}{ HDL (mg/dl) } \\
\hline \multicolumn{7}{|l|}{ HDL z-score } \\
\hline LDL (mg/dl) & -0.23 & 0.03 & -0.19 & 0.07 & & \\
\hline LDL z-score & & & -0.19 & 0.08 & & \\
\hline \multicolumn{7}{|l|}{$\mathrm{TG}(\mathrm{mg} / \mathrm{dl})$} \\
\hline \multicolumn{7}{|l|}{ Glucose (mg/dl) } \\
\hline \multicolumn{7}{|l|}{ Insulin $(\mathrm{mIU} / \mathrm{ml})$} \\
\hline QUICKI & 0.23 & 0.03 & & & & \\
\hline GDI & & & -0.22 & 0.06 & & \\
\hline HOMA-IR & -0.20 & 0.061 & & & & \\
\hline AIR (mIU/ml) & & & -0.42 & 0.0003 & -0.33 & 0.006 \\
\hline \multicolumn{7}{|l|}{ Adiponectin $(\mu \mathrm{g} / \mathrm{ml})$} \\
\hline IL-6 (pg/ml) & -0.32 & 0.003 & -0.18 & 0.09 & & \\
\hline \multicolumn{7}{|l|}{$\mathrm{CRP}(\mu \mathrm{g} / \mathrm{ml})$} \\
\hline \multicolumn{7}{|l|}{ TNF-a (pg/ml) } \\
\hline sRAGE (pg/ml) & 0.20 & 0.06 & & & 0.64 & $<0.0001$ \\
\hline \multicolumn{7}{|l|}{ Testosterone (males; ng/dl) } \\
\hline Estradiol (females; pg/ml) & & & & & -0.25 & 0.081 \\
\hline
\end{tabular}

\section{Correlation of sRAGE and esRAGE with}

Anthropometric Data and Metabolic Markers

sRAGE was significantly negatively correlated with multiple indices of body fatness [\% fat $(\mathrm{r}=-0.3, \mathrm{p}=$ $0.003)$, and fat mass $(r=-0.36, p=0.0007)$, fig. $2 a, b]$ but not with BMI $\mathrm{z}$-score, dyslipidemia [LDL $(\mathrm{r}=-0.2, \mathrm{p}=$ $0.07)$, LDL $z$-score $(r=-0.19, p=0.08)]$, or indices of insulin release [AIR $(\mathrm{r}=-0.42, \mathrm{p}=0.0003)$, fig. $2 \mathrm{c}$, and GDI $(r=-0.22, p=0.06)]$. Because sRAGE was negatively correlated with body fatness, data were also analyzed by multiple regression to adjust for BMI z-score. After this correction, sRAGE remained significantly negatively correlated with AIR (semipartial $r=-0.40$, $\mathrm{p}<0.001$ ), and a trend was noticed toward a negative correlation with GDI (semipartial $\mathrm{r}=-0.21, \mathrm{p}=0.057$, NS) but was no longer significantly correlated with any lipid values.
esRAGE was significantly negatively correlated with phase 1 insulin release (AIR; $r=-0.33, p=0.006$; table 2; fig. 3a) and was significantly positively correlated with $\operatorname{sRAGE}(\mathrm{r}=0.64, \mathrm{p}<0.0001$; table 2 ; fig. $3 \mathrm{~b})$.

\section{Discussion}

The major findings of this study are: (1) As in adults, sRAGE and esRAGE are, to varying degrees, negatively correlated with body fatness (both BMI and waist $\mathrm{z}$ scores), insulin resistance, insulin secretory capacity, LDL, and IL-6. (2) Unlike adults, CML is negatively associated with adiposity, LDL, and IL-6. To the best of our knowledge, this is the largest pediatric study to simultaneously examine the association between serum CML, sRAGE and esRAGE and adiposity, glucose homeostasis, 


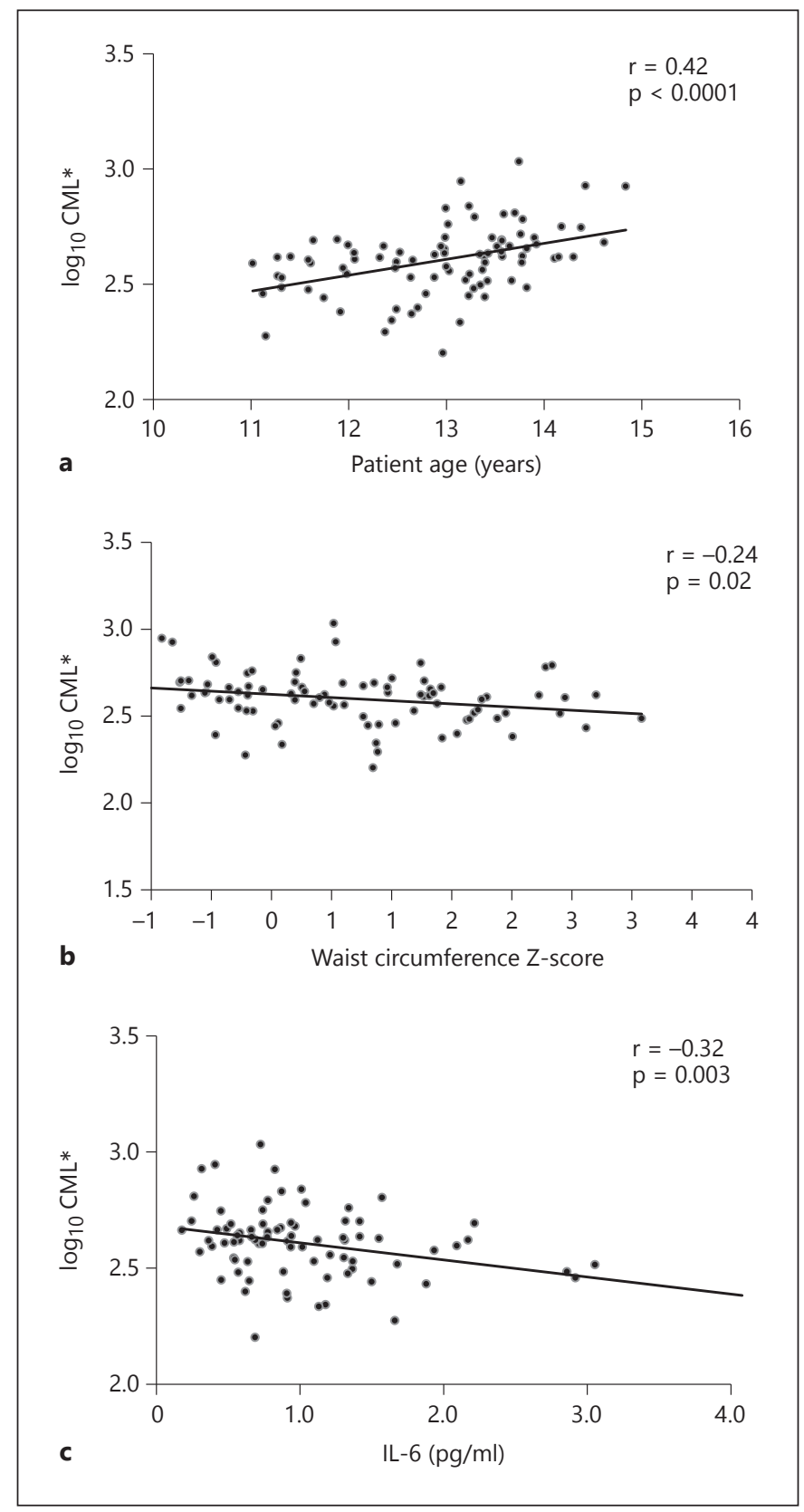

Fig. 1. Correlation of $\log _{10} \mathrm{CML}$ with chronological age (a), waist circumference Z-score (b), and IL-6 (c).

and inflammation in a diverse population of healthy middle school-age children in early to mid-adolescence. Sebekova et al. [10] studied a small cohort of 36 children and adolescents (4-18 years of age) and found a significantly lower level of plasma CML in obese children in comparison to their lean counterparts with no intergroup difference in sRAGE concentration (plasma esRAGE was not evaluated). Similar to the study by Sebekova et al. [10], we

AGE, RAGE and Comorbidity Risk Factors in Children

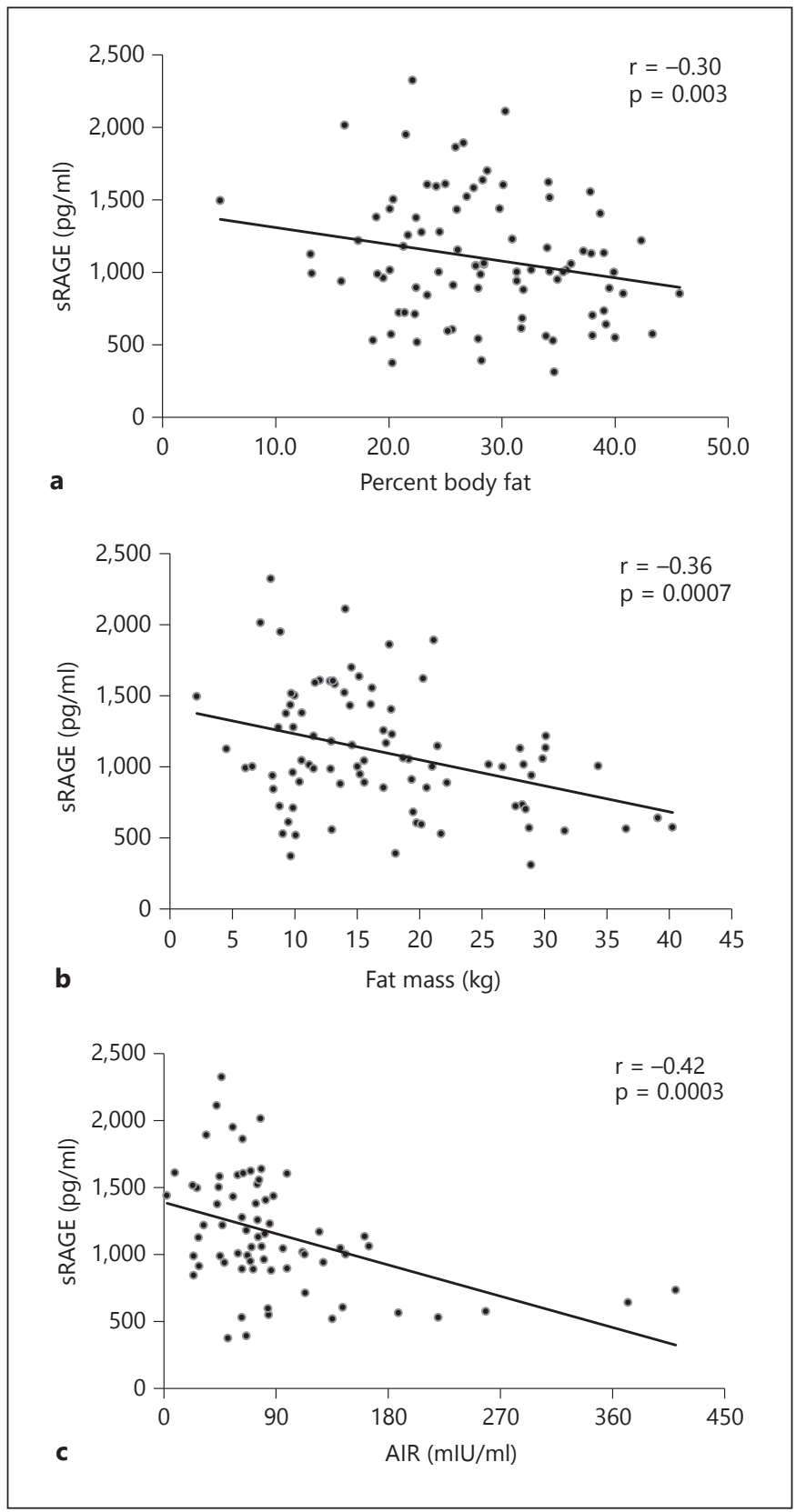

Fig. 2. Correlation of sRAGE with percent body fat (a), fat mass (b), and AIR (c).

found an inverse relationship between $\log _{10} \mathrm{CML}$ and the multiple markers of adiposity and adiposity-related comorbidity risk factors (IL-6, and LDL). However, Sebekova did not find the inverse association between sRAGE and indices of body fatness and insulin release seen in our study and in many adult studies [26]. In contrast to Sebekova et al. [10], a recent study of 130 prepubertal children (younger than those examined in the present study) 


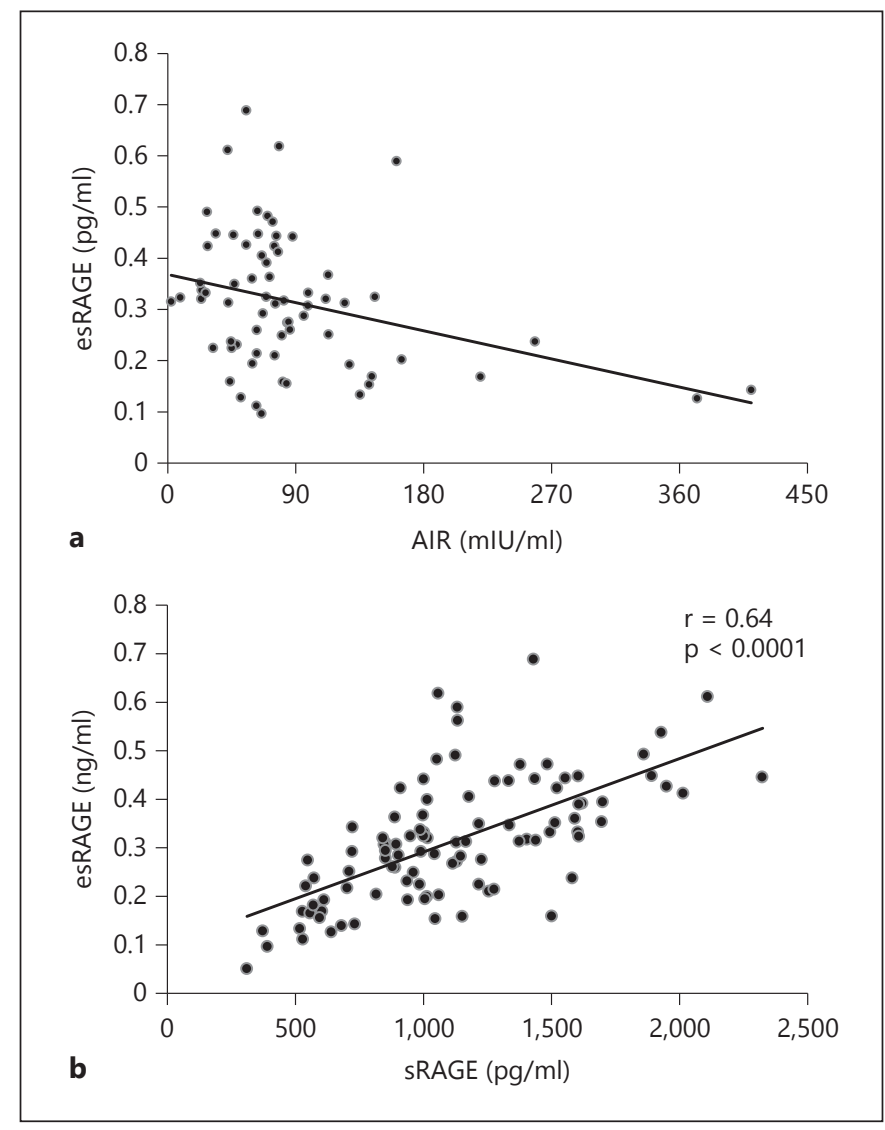

Fig. 3. Correlation of esRAGE with $\operatorname{AIR}(\mathbf{a})$, and sRAGE (b).

by Chiavaroli et al. [11] reported significant negative correlations of both sRAGE and esRAGE with adiposity and insulin resistance and also noted independently lower concentrations of sRAGE and esRAGE in children who were at increased risk of adiposity-related comorbidities by virtue of being small or large for gestational age. The present study demonstrates these same negative correlations of sRAGE and esRAGE in older children in early to mid-puberty. It is worth noting that the significant correlations of CML, sRAGE, and esRAGE with absolute adiposity (fat mass) were not reciprocated by significant correlations relative to adiposity (BMI Z-score), nor were they evident when subjects were overweight $(\mathrm{BMI}>85$ th percentile), obese (BMI $>95$ th percentile) or not overweight (BMI <85th percentile). These analyses suggest that in peripubertal children, circulating concentrations of advanced glycation products and their receptors are more closely related to fat mass than to age- and genderadjusted fatness.

The majority of adult and animal studies found a direct correlation between CML, body fatness and compo- nents of metabolic syndrome, unlike the findings in the present study [8, 9, 11, 27-29]. Gugliucci et al. [8] noted that serum AGE levels were directly correlated with BMI, waist circumference and TG in 37 healthy obese and overweight adults following weight loss after being on a low calorie diet. Despite the significant positive correlation that we observed between CML and age, there were no significant correlations observed between CML and sex steroids, suggesting that the increasing CML with age may be primarily a temporal effect (perhaps reflecting dietary CML) rather than an effect of sexual maturation. Tahara et al. [29] demonstrated that serum AGE levels were independently positively correlated with the HOMA-IR index in adult nondiabetic subjects. However, consistent with our findings, a large study of communitydwelling men and women recently showed that body fat mass, fasting plasma glucose, oral glucose tolerance, and insulin resistance were not significant determinants of serum CML [30]. Whether serum CML concentrations are affected by fat mass is not known. In adipocytes, CD36, a scavenger receptor, has the ability to bind AGE [31]. As a result, fat mass could possibly affect circulating AGE concentrations through a role in the catabolism and breakdown of AGE. This speculation is based on previous in vitro studies of both murine and human adipocytes that showed binding of AGE with CD-36 is followed by endocytosis and degradation of adipocytes. Therefore, this could be a physiologic mechanism to clear AGE from the circulation [31].

Although our extended statistical analysis showed a negative correlation between $\log _{10} \mathrm{CML}$ and LDL, it is still possible that glycation of lipids ultimately contributes to the unfavorable lipid profile in overweight and obese children and adolescents. Stitt et al. [32] showed that tissue AGE correlates with concentrations of plasma AGEmodified LDL in euglycemic, normolipidemic adults with atherosclerosis compared to young, normal controls. Therefore, it is worthwhile to consider that over a time period of many years, advanced glycation also may contribute to the age-related development of atherosclerosis in the general population since we also found a direct correlation between $\log _{10} \mathrm{CML}$ and chronological age in our study population. Moreover, Galler et al. [33] noted serum levels of fluorescent AGEs, but not of CMLAGEs, to be significantly higher in children and adolescents with diabetes compared to control subjects, and that subjects with diabetes and high serum cholesterol and TG also had significantly higher levels of serum fluorescent AGEs. Whether other forms of AGEs, rather than CML, play a role in dyslipidemia associated with diabetes in pe- 
diatric population remains to be determined. A recent observational study showed that LDL did not differ by tertiles of serum CML in adults [32].

A key question is whether AGEs are a cause or a symptom of adiposity and its related comorbidities. In a murine model of type 2 diabetes $\left(\right.$ Lepr $\left.^{d b / d b}\right)$ [27] and in diet-induced obese [28] mice, administration of a lowversus high-AGE diet resulted in improved glucose homeostasis, inflammation, and lipid panels. The animals fed the high-AGE diet were ultimately fatter and had more visceral fat than the low-AGE diet mice. The improvements in glucose homeostasis, inflammation, and lipids were evident before the weight differences between dietary groups were apparent in $L e p r^{d b / d b}$ mice [27] and disproportionately improved relative to a small difference in body weight in the diet-induced obese mice [28]. The disproportionately large improvement in adiposity-related comorbidity risk factors compared to differences in body composition between the mice fed high- and low-AGE diets suggests that the AGE itself not only favors weight gain but also worsens complications of that gain.

Studies, mainly in adults, indicate that CML promotes inflammation and is also a marker of ongoing inflammation. Incubation of human macrophages with CML has been shown to induce production of proinflammatory cytokines [34], and CML production is induced at sites of inflammation in the adult population [35]. However, studies of healthy children and adults $[10,36]$ have not reported significant correlations of CML with circulating concentrations of proinflammatory cytokines even though both CML and pro-inflammatory cytokines are elevated in pediatric and adult inflammatory conditions and ingestion of high CML diets in adults has been shown to be correlated with higher circulating concentrations of proinflammatory cytokines $[37,38]$. No studies, to our knowledge, have suggested a negative correlation of CML with inflammatory markers. One hypothesis is that our findings could be related to the type of population included in this study. The children included in our study were not selected previously for being at high risk of having elevated levels of cytokines.

Why then might a healthy population of children show a different pattern of association of CML with adiposityrelated comorbidity risk factors than adults, or compared with adults and children with inflammatory conditions? The simplest explanation would be that there are age-related differences in the absolute or relative circulating concentrations of CML, sRAGE, and or esRAGE which place them outside the range on the dose-response curve

AGE, RAGE and Comorbidity Risk Factors in Children at which 'adult' associations with adiposity-related comorbidity risk are evident. CML levels in our population of healthy middle school students were $\sim 20 \%$ below average adult levels $(\mathrm{p}<0.001)$, while circulating concentrations of sRAGE and esRAGE are approximately $70 \%$ higher than those reported in healthy adults (both $\mathrm{p}<$ 0.001) [25]. Another possibility, particularly relevant to the negative correlation of CML and IL-6, would be possible age- and health-related differences in the type of AGE-receptor expressed. Activation of the AGE receptor 1 (AGER1) suppresses cell inflammation and oxidant stress, and its expression is downregulated in inflammatory conditions, such as diabetes, and negatively associated with circulating concentrations of AGEs [39]. Restriction of intake of AGEs is associated with increased AGER1 and sirtuin (SIRT1) and increased insulin sensitivity [40]. In addition, AGER1 expression diminishes with age [41]. It is possible that within the range of low CML and increased AGER1 in this population of healthy children, there is actually a negative correlation of circulating CML, and thereby increased AGER1 activation, with inflammation and insulin sensitivity. At higher CML and lower AGER1 levels, the greater relative activation of other AGE receptors might increase oxidant stress rather than decrease it. In addition, as suggested by Hudson et al. [42], different genetic backgrounds are probably the explanation for the different CML levels as well as different amount of receptors found, considering that the majority of the population studied is non-Caucasian.

In our study population, we did not observe any significant correlation between $\log _{10} \mathrm{CML}$ and sRAGE or esRAGE. Although CML is used in most studies, and serum level of sRAGE may reflect tissue RAGE expression in nondiabetic healthy subjects, it is not exactly known which of the different AGE proteins is responsible for or associated with increased oxidative stress and inflammatory markers [43]. As discussed earlier, the relationship between AGEs and their receptors may be quite different in the range of lower concentration of AGEs. AGEs are a complex and heterogeneous group of proteins, and only the structures of some AGEs have been identified. Best characterized are pentosidine and CML. However nonAGEs, such as S100A12 proteins, have also been associated with activation of AGE receptors and could mediate the initiation of the inflammatory cascade. So far, no universally accepted method to detect AGEs or an internationally recognized standard unit of measurement exists [44]. One of the most common methods of measurement used is competitive ELISAs. Recently, a competitive ELISA using a monoclonal antibody recognizing CML 
became commercially available, and this may facilitate AGE determination in clinical practice [5]. AGEs have also been detected by other methods such as fluorescence spectroscopy or more advanced fast-protein liquid chromatography, high-performance liquid chromatography, and immunohistochemistry $[5,45]$.

The strength of this study is the inclusion of a diverse population of healthy children. Most studies examining AGEs and their receptors have involved adults or individuals with chronic inflammatory diseases such as diabetes, kidney disease and atherosclerosis where there is a broader and higher range of AGEs than are evident in this study $[8,9,11,20]$. The weaknesses of this study are largely related to its cross-sectional design. In addition, in this study the AGE content of the children's diet was unknown. As a cross-sectional study, it does not elucidate the causal relationships between serum CML, sRAGE and anthropometric, metabolic, and inflammatory variables, i.e. issues better examined in a longitudinal study. Because CML concentrations could potentially be influenced by increased glomerular filtration rate with increased BMI, another limitation of this study is that renal function test was not measured in this observational study. Although this type of study could potentially be carried out in all age groups, our study is limited to middle school students for several reasons. Students in this age group are likely to reflect all stages of puberty, permitting the assessment of the effects of progression of puberty in relationship to predictor and outcome variables. A similar study of older students would represent a developmentally less diverse population and is also more likely to be confounded by other variables such as pregnancy, substance abuse, and T2DM. Younger students would also be less diverse and would have questionable ability to reliably assent to biochemical testing. We also recognize that while this early to mid-pubertal age group may represent the most logical choice for this study, it could account as a limitation for this study.

In summary, our study included 88 middle school-age children, representing a wide range of insulin resistance with multi-ethnic/-racial background. To our knowledge, this is the largest multi-ethnic/-racial study investigating the correlation between AGE, sRAGE, esRAGE and markers of obesity-related comorbidity risk factors in healthy adolescents. While AGEs have been implicated as a possible cause of oxidative stress in adult studies, the role of AGE level in healthy nonobese adolescents is less clear. It may be that the effects of AGEs are cumulative and may not have immediate deleterious effects on healthy children, at least at the time they are in middle school. At what time in life the correlations found in adults begin to occur will require future longitudinal studies of children as they grow into adulthood.

\section{Acknowledgements}

We would like to gratefully acknowledge the invaluable participation of all the students, teachers, and school administrators, as well as the NYC Board of Health and Department of Education. Funding was received through $\mathrm{AMDeC}$ by the Starr Foundation, as well as with support from NIH grant numbers UL1 RR0023568 and UL1 RR000040. We wish to thank Prof. Paul Saenger and Steve Holleran, $\mathrm{PhD}$, for their helpful discussion in preparation of the manuscript.

\section{References}

1 Rosenbaum M: Epidemiology of pediatric obesity. Pediatr Ann 2007;36:89-95.

- 2 Unger R, Kreeger L, Christoffel KK: Childhood obesity. Medical and familial correlates and age of onset. Clin Pediatr (Phila) 1990;29: 368.

3 Matsuzawa Y, Funahashi T, Nakamura T: The concept of metabolic syndrome: contribution of visceral fat accumulation and its molecular mechanism. J Atheroscler Thromb 2011;18: 629-639.

4 Baynes JW, Thorpe SR: Role of oxidative stress in diabetic complications: a new perspective on an old paradigm. Diabetes 1999; 48:1-9.

5 Goldin A, Beckman JA, Schmidt AM, Creager MA: Advanced glycation end products: sparking the development of diabetic vascular injury. Circulation 2006;114:597-605.
-6 Kwon, J-H, Kim YH, Kwon JY, Park YW: Clinical significance of serum sRAGE and esRAGE in women with normal pregnancy and preeclampsia. J Perinat Med 2011;30: 507-513.

-7 D’Adama Giannini C, Chiavaroli V, de Giorgis T, Verrotti A, Chiarelli F, Mohn A: What is the significance of soluble and endogenous secretory receptor for advanced glycation end products in liver steatosis in obese prepubertal children. Antioxid Redox Signal 2011;14:11671172.

-8 Gugliucci A, Kotani K, Taing J, Matsuoka Y, Sano Y, Yoshimura M, Egawa K, Horikawa C, Kitagawa Y, Kiso Y, Kimura S, Sakane N: Short term low calorie diet intervention reduces serum advanced glycation end products in healthy overweight or obese adults. Ann Nutr Metab 2009;54:197-201.
9 Schmidt A, Schmidt AM, Yan SD, Yan SF, Stern DM: The multiligand receptor RAGE as a progression factor amplifying immune and inflammatory responses. J Clin Invest 2001; 108:949-955.

10 Sebeková K, Somoza V, Jarcusková M, Heidland A, Podracká L: Plasma advanced glycation end products are decreased in obese children compared with lean controls. Int J Pediatr Obes 2009;4:112-118.

11 Chiavaroli V, D’Adamo E, Giannini C, de Giorgis T, De Marco S, Chiarelli F, Mohn A: Serum levels of receptors for advanced glycation end products in normal-weight and obese children born small and large for gestational age. Diabetes Care 2012;35:1361-1363.

12 Peppa M, Raptis S: Advanced glycation end products and cardiovascular disease. Curr Diab Rev 2008;4:92-100. 
$\checkmark 13$ Rosenbaum M, Accacha SD, Altshuler LA, Carey DE, Fennoy I, Lowell BC, Rapaport R, Speiser PW, Shelov SP: The Reduce Obesity and Diabetes (ROAD) project: design and methodological considerations. Child Obes 2011;7:223-234.

14 American Physiological Society, World Medical Association General Assembly: Guiding principles for research involving animals and human beings. Am J Physiol Regul Integr Comp Physiol 2002;283:R281-R283.

15 Rosenbaum M, Nonas C, Horlick M, Fennoy I, Vargas I, Schachner H, Kringas P, Stanton K, Weil R, Camino Diabetes Prevention Group: Beta-cell function and insulin sensitivity in early adolescence: association with body fatness and family history of type 2 diabetes mellitus. J Clin Endocrinol Metab 2004; 89:5469-5476.

16 Katz A, Nambi SS, Mather K, Baron AD, Follmann DA, Sullivan G, Quon MJ: Quantitative insulin sensitivity check index: a simple, accurate method for assessing insulin sensitivity in humans. J Clin Endocrinol Metab 2000;85: 2402-2410.

17 Zethelius B, Byberg L, Hales CN, Lithell H, Berne C: Proinsulin and acute insulin response independently predict type 2 diabetes mellitus in men - report from 27 years of follow-up study. Diabetologia 2003;46:20-26.

-18 Kahn SE: The relative contributions of insulin resistance and beta-cell dysfunction to the pathophysiology of type 2 diabetes. Diabetologia 2003;46:3-19.

19 Flegal K, Cole T: Construction of LMS parameters for the centers for disease control and prevention 2,000 growth charts. National Health Statistics Reports. 2013, vol 63.

20 Ford ES, Mokdad AH, Ajani UA: Trends in risk factors for cardiovascular disease among children and adolescents in the United States. Pediatrics 2004;114:1534-1544.

21 Hickman TB, Briefel RR, Carroll MD, Rifkind BM, Cleeman JI, Maurer KR, Johnson CL: Distributions and trends of serum lipid levels among United States children and adolescents ages $4-19$ years: data from the Third National Health and Nutrition Examination Survey. Prev Med 1998;27:879-890.

-22 Perneger TV: What's wrong with Bonferroni adjustments. BMJ 1998;316:1236-1238.

23 Rothman KJ: No adjustments are needed for multiple comparisons. Epidemiology 1990;1: 43-46.

24 Thomas DC, Siemiatycki J, Dewar R, Robins J, Goldberg M, Armstrong BG: The problem of multiple inference in studies designed to generate hypotheses. Am J Epidemiol 1985; 122:1080-1095.
5 Yang SJ, Kim S, Hwang SY, Kim TN, Choi HY, Yoo HJ, Seo JA, Kim SG, Kim NH, Baik SH, Choi DS, Choi KM: Association between sRAGE, esRAGE levels and vascular inflammation: analysis with (18)F-fluorodeoxyglucose positron emission tomography. Atherosclerosis 2012;220:402-406.

26 Norata GD, Garlaschelli K, Grigore L, Tibolla G, Raselli S, Redaelli L, Buccianti G, Catapano AL: Circulating soluble receptor for advanced glycation end products is inversely associated with body mass index and waist/hip ratio in the general population. Nutr Metab Cardiovasc Dis 2009;19:129-134.

27 Hofmann SM, Dong HJ, Li Z, Cai W, Altomonte J, Thung SN, Zeng F, Fisher EA, Vlassara $\mathrm{H}$ : Improved insulin sensitivity is associated with restricted intake of dietary glycoxidation products in the $\mathrm{db} / \mathrm{db}$ mouse. Diabetes 2002;51:2082-2089.

28 Sandu O, Song K, Cai W, Zheng F, Uribarri J, Vlassara H: Insulin resistance and type 2 diabetes in high fat fed mice are linked to high glycotoxin intake. Diabetes 2005;54:2314-2319.

29 Tahara R, Yamagishi SI, Matsui T: Serum levels of advanced glycation end products (AGEs) are independent correlates of insulin resistance in nondiabetic subjects. Cardiovasc Ther 2012;30:42-48.

30 Semba RD, Arab L, Sun K, Nicklett EJ, Ferrucci L: Fat mass is inversely associated with serum carboxymethyl-lysine, an advanced glycation end product, in adults. J Nutr 2011;141: 1726-1730

31 Kuniyasu A, Ohgarni N, Hayashi S, Miyazaki A, Horiuchi S, Nakayama H: CD36-mediated endocytic uptake of advanced glycation end products (AGE) in mouse $3 \mathrm{~T} 3-\mathrm{Ll}$ and human subcutaneous adipocytes. FEBS Lett 2003; 537:85-90.

32 Stitt AW, He C, Friedman S, Scher L, Rossi P, Ong L, Founds H, Li YM, Bucala R, Vlassara $\mathrm{H}$ : Elevated AGE-modified ApoB in sera of euglycemic, normolipidemic patients with atherosclerosis: relationship to tissue AGEs. Mol Med 1997;3:617-627.

33 Galler A, Müller G, Schinzel R, Kratzsch J, Kiess W, Münch G: Impact of metabolic control and serum lipids on the concentration of advanced glycation end products in the serum of children and adolescents with type 1 diabetes, as determined by fluorescence spectroscopy and $\mathrm{N}$-(carboxymethyl) lysine ELISA. Diabetes Care 2003;26:2609-2615.

34 Pertyńska-Marczewska M, Kiriakidis S, Wait R, Beech J, Feldmann M, Paleolog EM: Advanced glycation end products upregulate angiogenic and pro-inflammatory cytokine production in human monocyte/macrophages. Cytokine 2004;28:35-47.

- 35 Anderson MM, Requena JR, Crowley JR, Thorpe SR, Heinecke JW: The myeloperoxidase system of human phagocytes generates $\mathrm{N}$ (carboxymethyl)lysine on proteins: a mechanism for producing advanced glycation end products at sites of inflammation. J Clin Invest 1999;104:103-113.
36 Vlassara H: Advanced glycation in health and disease: role of the modern environment. Ann NY Acad Sci 2005;1043:452-460.

- 37 Sebeková K, Podracká L, Heidland A, Schinzel R: Enhanced plasma levels of advanced glycation end products (AGE) and pro-inflammatory cytokines in children/adolescents with chronic renal insufficiency and after renal replacement therapy by dialysis and transplantation - are they inter-related? Clin Nephrol 2001;56:S21-S26.

38 Uribarri J, Cai W, Peppa M, Goodman S, Ferrucci L, Striker G, Vlassara H: Circulating glycotoxins and dietary advanced glycation endproducts: two links to inflammatory response, oxidative stress, and aging. J Gerontol A Biol Sci Med Sci 2007;62:427-433.

39 Cai W, He JC, Zhu L, Lu C, Vlassara H: Advanced glycation end product (AGE) receptor 1 suppresses cell oxidant stress and activation signaling via EGF receptor. Proc Natl Acad Sci USA 2006;103:13801-13806.

- 40 Uribarri J, Cai W, Ramdas M, Goodman S, Pyzik R, Chen X, Zhu L, Striker GE, Vlassara $\mathrm{H}$ : Restriction of advanced glycation end products improves insulin resistance in human type 2 diabetes: potential role of AGER1 and SIRT1. Diabetes Care 2011;34:16101616.

41 Vlassara H, Uribarri J, Cai W, Striker G: Advanced glycation end product homeostasis: exogenous oxidants and innate defenses. Ann N Y Acad Sci 2008; 1126:46-52.

-42 Hudson BI, Moon YP, Kalea AZ, Khatri M, Marquez C, Schmidt AM, Paik MC, Yoshita M, Sacco RL, DeCarli C, Wright CB, Elkind MS: Association of serum soluble receptor for advanced glycation end-products with subclinical cerebrovascular disease: the Northern Manhattan Study (NOMAS). Atherosclerosis 2011;216:192-198.

43 Nakamura K, Adachi H, Matsui T, Kurita Y, Takeuchi M, Yamagishi S: Independent determinants of soluble form of receptor for advanced glycation end products in elderly hypertensive patients. Metabolism 2009;58: 421-425.

44 Koga M, Otsuki M, Matsumoto S, Saito H, Mukai M, Kasayama S: Negative association of obesity and its related chronic inflammation with serum glycated albumin but not glycated hemoglobin levels. Clin Chem Acta 2007;378:48-52.

-45 Ikeda K, Higashi T, Sano H, Jinnouchi Y, Yoshida M, Araki T, Ueda S, Horiuchi S: N(carboxymethyl) lysine protein adduct is a major immunological epitote in proteins modified with advanced glycation end products of the Maillard reaction. Biochemistry 1996;35:8075-8083.
AGE, RAGE and Comorbidity Risk Factors in Children
Horm Res Paediatr 2013;80:318-327 DOI: $10.1159 / 000354831$ 